\title{
ENTRE CONVERGÊNCIAS, CONVENIÊNCIAS E IMPACTOS: UMA ANÁLISE COMPARATIVA DOS PDI 2004 E 2013 DA UFSCAR COM BASE NO REUNI
}

\author{
BETWEEN CONVERGENCES, CONVENIENCES AND IMPACTS: \\ A COMPARATIVE ANALYSIS OF THE 2004 AND 2013 PDI FROM \\ UFSCAR BASED ON THE MEETING
}

\begin{abstract}
ENTRE CONVERGENCIAS, CONVENIENCIAS E IMPACTOS: UN ANÁLISIS COMPARATIVO DE LOS PDI 2004 Y 2013 DE UFSCAR BASADOS EN LA REUNIÓN
\end{abstract}

GÉSSICA Priscila RAMOS

Ana Paula Silveira ${ }^{\underline{I I}}$

Priscila de Paulo Uliam Martins ${ }^{\text {III }}$

IUniversidade Federal de São Carlos (UFSCAR), São Carlos/SP-Brasil

IUniversidade Federal de São Carlos (UFSCAR), São Carlos/SP-Brasil

IIIUniversidade Federal de São Carlos (UFSCAR), São Carlos/SP-Brasil

Resumo O objetivo deste artigo é verificar o impacto do Programa de Apoio a Planos de Reestruturação e Expansão das Universidades Federais (Reuni) no planejamento estratégico da Universidade Federal de São Carlos (UFSCar), a partir do estudo comparativo de seus dois Planos de Desenvolvimento Institucional (PDI) - 2004 e 2013. Este trabalho tem base em análise bibliográfica e documental e se configura a partir das seguintes categorias de estudo: Ampliação da Oferta de Educação Superior Pública; Reestruturação Acadêmico-Curricular; Renovação Pedagógica da Educação Superior; Mobilidade Intra e Interinstitucional; Compromisso Social da Instituição; Suporte da Pós-Graduação ao Desenvolvimento e Aperfeiçoamento Qualitativo dos Cursos de Graduação. Constatou-se que a adesão da UFSCar ao Reuni, em 2007, pode ser entendida como uma ação política de conveniência da gestão da Universidade para recebimento de verbas para consolidação de suas ações, metas e mecanismos de regulação já previstos no seu primeiro PDI 2004. Apesar da conveniência da adesão, pode-se concluir que o referido Programa acabou atuando de forma profunda no planejamento estratégico da Instituição ao exercer forte impacto em seu PDI 2013, gerando novas demandas e ênfases, bem como o aprofundamento de algumas delas, agindo no sentido de intensificar 
ações e políticas reguladoras da UFSCar com vistas ao cumprimento do Contrato de Adesão firmado com o MEC em um contexto de precariedade orçamentária.

Palavras-chave: Ensino Superior; REUNI; Administração das Instituições de Ensino Superior.

Abstract The purpose of this article is to verify the impact of the Support Program for Federal University Restructuring and Expansion Plans (Reuni) in the strategic planning of the Federal University of São Carlos (UFSCar), built around a comparative study of two Institutional Development Plans (PDI) - 2004 and 2013. This study is based on bibliographic and documentary analysis and in the following categories of analysis: Expansion of the Public Higher Education Offer; Academic-Curricular Restructuring; Pedagogical Renewal of Higher Education; Intra and Interinstitutional Mobility; Institution's Social Commitment; and Graduate Support for the Development and Qualitative Improvement of Undergraduate Courses. It turned out that UFSCar's adhesion to Reuni, in 2007, can be understood as a political action of convenience for the University's management, to receive funds to consolidate actions, goals and regulatory mechanisms already foreseen in its first PDI 2004. Despite the convenience of joining, it can be concluded that the referred program ended up having a profound effect in the Institution's strategic planning by having a strong impact on its PDI 2013, generating new demands and emphases, as well as the deepening of some of them, acting to intensify actions and UFSCar's regulatory policies with the aim of complying with the Adhesion Contract signed with MEC in the context of budgetary precariousness.

Keywords: Higher Education; REUni; Administration of Higher Education InstituTIONS.

REsumen El propósito de este artículo es verificar el impacto del Programa de Apoyo a los Planes de Expansión y Reestructuración de la Universidad Federal (Reuni) en la planificación estratégica de la Universidad Federal de São Carlos (UFSCar), basado en un estudio comparativo de sus dos Planes de Desarrollo Institucional (PDI) - 2014 y 2013. Este estudio se basa en el análisis bibliográfico y documental y en las siguientes categorías de análisis: Expansión de la Oferta Pública de Educación Superior; Reestructuración Académico-Curricular; Renovación Pedagógica de la Educación Superior; Movilidad Intra e Interinstitucional; Compromiso Social de la Institución; Apoyo de Posgrado para el Desarrollo y la Mejora Cualitativa de los Cursos de Pregrado. Se descubrió que la adhesión de UFSCar a Reuni, en 2007, puede entenderse como una acción política de conveniencia para que la gerencia de la Universidad reciba fondos para consolidar sus acciones, objetivos y mecanismos regulatorios ya previstos en su primer PDI 2004. A pesar de la conveniencia de unirse, se puede concluir que el referido programa terminó teniendo un profundo efecto en la planificación estratégica de la Institución al tener un fuerte impacto en su PDI 2013, generando nuevas demandas y énfasis, así como la profundización de algunos de ellos, actuando para intensificar las acciones y las políticas regulatorias de UFSCar con el fin de cumplir con el Contrato de Adhesión firmado con el MEC en un contexto de precariedad presupuestaria.

Palabras clave: Educación Superior; REUni; Administración de Instituciones de EduCACIÓN SUPERIOR. 


\section{INTRODUÇ̃̃̃o}

A Universidade Federal de São Carlos (UFSCar) aprovou, em 2002, a constituição do processo de elaboração de seu Plano de Desenvolvimento Institucional (PDI) para vigência a partir de 2004 e com previsão de vinte anos de validade. As diretrizes do PDI da UFSCar nasceram no contexto pós criação do Grupo de Trabalho Interministerial, instituído, segundo Otranto (2006), pelo Governo Federal, em 20 de outubro de 2003, que tinha o objetivo de analisar a situação das Instituições Federais de Ensino Superior (IFES) e apresentar um plano de ação para reestruturar, desenvolver e democratizá-los.

Não por acaso, o PDI 2004 UFSCar (UFSCAR, 2004) contemplava várias diretrizes voltadas para o desenvolvimento e democratização da Universidade. Ele era composto internamente pelos seguintes tópicos: Princípios, Diretrizes Gerais e Diretrizes Específicas, Diretrizes para o Desenvolvimento Físico, Diretrizes para Aperfeiçoamento da Estrutura Organizacional e A Implementação do Plano. Todos esses tópicos se alinhavam aos seus Princípios, que acenavam para:

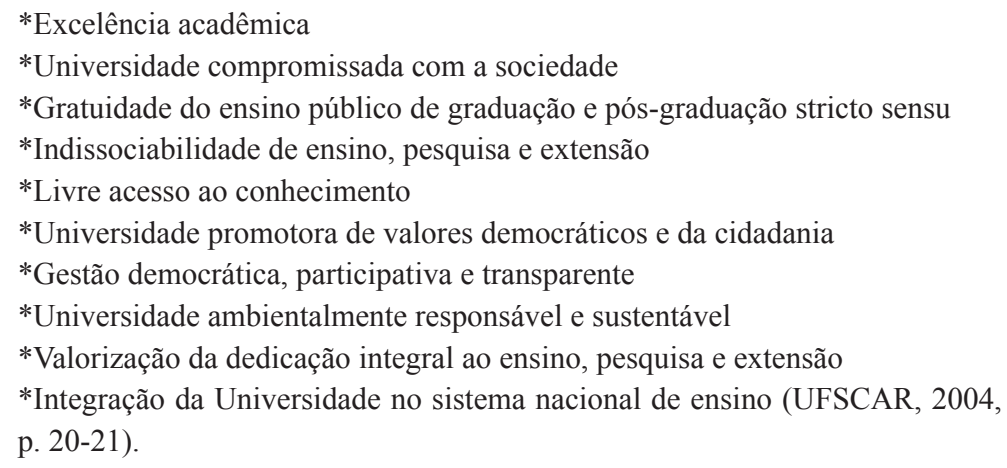

Vale ressaltar que o PDI 2004 UFSCar anunciou a necessidade de expansão da supracitada Universidade, que já era prevista pelo MEC desde 2003, quando indicava objetivar: "Expandir o sistema federal de ensino superior, com vistas a ampliar o acesso à universidade, promover a inclusão social e reduzir as desigualdades regionais" (BRASIL, 2006b, p. VI). Assim, não por acaso, quase paralelamente à elaboração e lançamento do referido PDI, o Governo Federal também lançava o seu Programa de Expansão do Sistema Federal de Educação Superior, ${ }^{1}$ chamado Expandir, que contava com a UFSCar como uma de suas instituições tutoras e colaboradoras na implantação das novas universidades. Ele teve adesão pela UFSCar, em 2005, passando a auxiliar na consolidação inicial da expansão proposta em seu PDI 2004 (LOURENÇO, 2016) e contribuindo para a consolidação, de acordo com Lourenço (2016), de um novo campus da UFSCar no município de Sorocaba, que ofereceria 180 vagas, distribuídas em quatro cursos de graduações presenciais: Biologia, Licenciatura em Biologia, Turismo e Engenharia de Produção.

1 Programa de Expansão do Sistema Federal de Educação Superior - "Expandir" 2003-2006, que tinha como metas fortalecer, ampliar e interiorizar o ensino superior público e gratuito no Brasil (BRASIL, 2006b). Essa política pública de expansão do ensino superior foi realizada no primeiro mandato do Governo Lula e reconhecia a Universidade como elemento estratégico para o desenvolvimento social e econômico do país. 
Tal Plano, embora criado com o objetivo de ter o prazo de vinte anos para sua implantação, foi substituído, em 2014, por um novo PDI, criado em 2013 e publicado no ano seguinte (UFSCAR, 2014a), com vistas a realizar redefinições nos rumos da Universidade. Para tanto, ele foi internamente reestruturado a partir dos seguintes tópicos: Diretrizes Gerais, Diretrizes Específicas e Diretrizes para Gestão do Espaço Físico dos Campi.

Essa substituição antecipada de PDI pela UFSCar foi decorrente das ações do Governo Federal, a partir de meados dos anos 2000, que lançou políticas como a Universidade Aberta do Brasil (UAB), ${ }^{2}$ as Ações Afirmativas ${ }^{3}$ e o Programa de Apoio a Planos de Reestruturação e Expansão das Universidades Federais (Reuni), medidas voltadas para a expansão da Universidade e para inclusão social por intermédio dela. De acordo com Lourenço (2016), tais políticas contribuíram para que os processos seletivos de ingresso na UFSCar passassem a prestigiar os critérios socioeconômicos e étnico-raciais, contribuindo para democratizar o seu acesso notadamente por volta de 2008, com a implantação do Reuni.

No caso específico desse Programa, ele foi instituído pelo Decreto n. 6.096, de 2007 (BRASIL, 2007a), com o objetivo de criar "condições para a ampliação do acesso e permanência na educação superior, no nível de graduação, pelo melhor aproveitamento da estrutura física e de recursos humanos existentes nas universidades federais" (BRASIL, 2007, art. 1º.). No documento intitulado "Reuni - Reestruturação e expansão das universidades federais: diretrizes gerais", de agosto de 2007, foram definidas seis dimensões a serem contempladas pelas IFES em seus projetos internos para procederem à adesão ao Reuni, sendo: a "Ampliação da Oferta de Educação Superior Pública"; a "Reestruturação Acadêmico-Curricular"; a "Renovação Pedagógica da Educação Superior; a Mobilidade Intra e Inter-Institucional"; o "Compromisso Social da Instituição; o Suporte da pós-graduação ao desenvolvimento e aperfeiçoamento qualitativo dos cursos de graduação" (BRASIL, 2007b, p. 11).

Tendo em vista a adesão voluntária da UFSCar ao Programa no ano de 2007 (BRASIL, 2007), bem como, as novas exigências que tais dimensões acarretariam à Instituição, a Universidade procedeu à atualização de seu PDI, tendo como pressuposto que:

[...] frente ao crescimento e às profundas transformações pelas quais passou a UFSCar nos últimos anos - especialmente a partir de 2009, com o Reuni (Programa de Apoio a Planos de Reestruturação e Expansão das Universidades Federais) -, parte das diretrizes aprovadas em 2004 estavam superadas e, também, havia temas ausentes ou pouco explorados no plano original (UFSCAR, on-line).

Tal reformulação, conforme o Relatório de Atividades de 2015 da UFSCar (UFSCAR, 2016), iniciou-se em 2011, quando o Conselho Universitário (ConsUni) aprovou a criação de

2 Universidade Aberta do Brasil (UAB) foi um Programa criado pelo Decreto $n^{\circ}$. 5.800, de 8 de junho de 2006, que objetivava ampliar e interiorizar a oferta de cursos e programas de educação superior, por meio da educação a distância; além disso, pretendia oferecer formação em nível superior aos profissionais da educação básica de todo o país. Os cursos foram oferecidos pelas IFES em todo território brasileiro (BRASIL, 2006a).

3 As Políticas de Ações Afirmativas destacadas aqui são referentes às ações para democratização da expansão e do acesso ao ensino, postas pela Lei $\mathrm{n}^{\circ}$. 12.711, de 29 de agosto de 2012. Tal Lei previa que as IFES reservassem, em seus processos seletivos para o ingresso nos cursos de graduação, vagas para estudantes: que tivessem cursado integralmente o ensino médio em escolas públicas; ou que fossem oriundos de famílias com renda igual ou inferior a 1,5 (IBGE) salário mínimo; ou que se autodeclarassem pretas, pardas e indígenas ou com deficiência (BRASIL, 2012). 
três Grupos de Trabalhos (Aspectos Acadêmicos; Aspectos Organizacionais; Aspectos Físico-Ambientais) para agir na atualização do PDI, notadamente por conta do impacto do Reuni, da UAB e das Políticas de Ação Afirmativas na Instituição. A atualização foi aprovada, em 2013, pelo ConsUni (UFSCAR, 2014b, p. 34), ao levar em conta os aspectos provenientes notadamente do impacto do Reuni na Instituição, considerando o crescimento da Universidade com a criação do campus Sorocaba e de Lagoa do Sino, e ao ter como foco avaliar essa experiência e a sua proposta organizacional para o funcionamento multicampi.

Toda essa mobilização realizada pela Universidade para a revisão de seu PDI revela que a adesão da UFSCar ao Reuni, em 2007, parece ter implicado a readequação formal de seus objetivos e ações de gestão com vistas a operar a implantação do Programa. Assim, considerando que, segundo Henriques (2016), o PDI se trata de um planejamento estratégico, elaborado por Instituições de Ensino Superior, composto por metas, objetivos, ações, estratégias, bem como, seus encaminhamentos de gestão, este artigo estabeleceu como objetivo verificar qual o impacto do Reuni no planejamento estratégico da UFSCar a partir do estudo comparativo de seus dois PDI.

Pela natureza de seu objeto, esta pesquisa é pautada em análise documental com suporte bibliográfico, tendo como ferramenta metodológica o que Kuenzer (1998) chama de categorias de conteúdo (KUENZER, 1998). Segundo a autora, tais categorias são definidas com base no objeto e na finalidade da investigação e auxiliam a conferir cientificidade e rigor à sistematização dos dados coletados, ao servirem como critério básico para coleta, seleção e organização da teoria e dos fatos pesquisados, tendo por base a própria finalidade da pesquisa.

Por isso, foram determinadas como categorias de estudo deste artigo as próprias dimensões destacadas pelo Reuni para a expansão e a democratização da Universidade, sendo: Ampliação da Oferta de Educação Superior Pública; Reestruturação Acadêmico-Curricular; Renovação Pedagógica da Educação Superior; Mobilidade Intra e Interinstitucional; Compromisso Social da Instituição; Suporte da Pós-Graduação ao Desenvolvimento e Aperfeiçoamento Qualitativo dos Cursos de Graduação.

Ressalta-se que este artigo integra uma pesquisa mais ampla que focou a Nova Gestão Pública e a reconfiguração da avaliação da educação superior na UFSCar a partir do Reuni, por meio do uso de pesquisa documental e de campo.

\section{ENTRE CONVERGÊNCIAS, CONVENIÊNCIAS E IMPACTOS}

Inicialmente, é importante se destacar que o documento do PDI 2004 (UFSCAR, 2004) e o documento do PDI 2013 (UFSCAR, 2014a) se diferenciam muito pelo formato de sua aparência visual: enquanto o primeiro é um documento completo em termos de apresentação, contendo capa, autoria, referências, imagens, princípios, diretrizes (gerais e específicas) e aspectos para a implementação do plano; o segundo é um documento sem capa, imagens, referência e indicação de autoria, que se limita a expor, de modo direto e em formato de quadros, suas diretrizes (gerais e específicas). Tal característica indica a possibilidade de o documento de 2013 (UFSCAR, 2014a) se tratar apenas de uma reapresentação revisada das diretrizes constantes do PDI 2004 (UFSCAR, 2004), sem, contudo, manter o cuidado com sua apresentação visual e com a inclusão do restante dos itens internos previstos em um Plano, gerando duas hipóteses possíveis: ou, supostamente, as partes de autoria, princípios e aspectos da implementação do 
plano se mantiveram no novo PDI, embora não tenham sido apresentadas; ou, simplesmente, essas partes não foram rediscutidas e, portanto, acabaram banidas do documento final, que se focou apenas na exposição das diretrizes de ação.

Pelo estudo do PDI 2004 (UFSCAR, 2004), fica explícito que a ideia de expansão da Universidade já estava presente na UFSCar muito antes da criação do Reuni, o que revela sua atuação e comprometimento prévio com o tema Ampliação da Oferta da Educação Superior. Tal afirmação pode ser corroborada em suas Diretrizes Gerais, que assinalavam o objetivo de ampliar o oferecimento de cursos e vagas nos cursos de graduação, pós-graduação e extensão, de acordo com estudos a respeito da demanda e do equilíbrio entre as áreas de conhecimento (UFSCAR, 2004). Desde então a ênfase da expansão recaia sobre o período noturno, de modo que, segundo o documento, seria priorizada a ampliação de seus cursos (UFSCAR, 2004). Tal assertiva reapareceria no PDI 2013 (UFSCAR, 2014a), seguindo a ênfase também presente no documento do Reuni (MEC, 2007b).

De acordo com Carvalho (2014), a tentativa de se obter o maior número de matrículas em cursos noturnos nas IFES se deu pois, na concepção dos idealizadores do Reuni, tais cursos contemplariam o acesso e a permanência no ensino superior ao possibilitar que seus estudantes continuassem exercendo suas funções laborais, tendo em vista o aumento no número de matrículas de alunos no ensino médio noturno das redes estaduais, no período de 2007 a 2010. A ideia, portanto, era que as IFES dessem condições de estudo para esses jovens com a ampliação da oferta de vagas nos cursos de graduação noturna. Ainda para Carvalho (2014), a abertura de cursos noturnos nas IFES, em 2008, foi incentivada na tentativa de alinhar essas Instituições às Instituições Privadas de Ensino Superior (IPES), com fim lucrativo, que apresentavam um maior índice de cursos noturnos.

Apesar da ênfase na ampliação do ensino noturno, a ideia de expansão presente no PDI 2004 aparecia também sob outras formas. Em suas Diretrizes, foram destacados procedimentos observáveis para organização sustentável da expansão física da Universidade, indicando que se deveria "manter um índice mínimo de área verde de $30 \mathrm{~m}^{2}$ por habitante (mais que o dobro do recomendado pela ONU para áreas urbanas)", compatibilizando a preservação de áreas e a destinação de espaços para a expansão urbana dos campi, conforme demandas acadêmicas de médio e/ou longo prazos (UFSCAR, 2004, p. 36).

De forma mais direta, o documento explicitava não apenas seu compromisso com a expansão do espaço, mas das vagas da Universidade. Isso foi exposto no tópico Diretrizes Específicas sobre ampliação, acesso e permanência, que deixava clara a indicação do compromisso da UFSCar em ampliar, de modo organizado e planejado, as vagas e cursos de graduação, pós-graduação e extensão (UFSCAR, 2004, p. 29).

Frente ao objetivo de expansão física e humana da Instituição e, por conseguinte, de ampliação do acesso e democratização do ensino superior brasileiro, e ao não antever apoio financeiro extra para essa empreitada - futuramente amparada pelo Reuni -, a Instituição criou, nas Diretrizes Específicas de seu PDI (UFSCAR, 2004), a previsão de ações para ampliação de sua captação de verbas, bem como, para a eficiência, racionalização e otimização de seus gastos. Assim, segundo o documento da Instituição, a UFSCar deveria buscar: aperfeiçoar seus processos administrativos com vistas à "agilidade, eficiência e economia de recursos"; "novas formas de captação de recursos para a Universidade, em consonância com seu caráter público 
e com a democratização do acesso" (UFSCAR, 2004, p.35); e aproveitar plenamente a capacidade "já instalada na UFSCar na ampliação do acesso à Universidade" (UFSCAR, 2004, p. 28).

Nesse contexto, a expansão da UFSCar exigiria ações sociais para suporte humano, destacando-se, nesse caso, o tema Compromisso Social da Instituição. Para isso, foram traçadas ações em seu PDI 2004 (UFSCAR, 2004), dentro de suas Diretrizes Gerais, que indicavam, entre seus nortes, o suporte social à comunidade universitária, tendo em vista "desenvolver e ampliar a concepção de atendimento e assistência à comunidade universitária" (UFSCAR, 2004, p. 22), bem como, promover e incentivar ações que ampliassem o acesso e a permanência dos estudantes na Universidade e, ao mesmo tempo, atuassem no enfrentamento do problema da exclusão social.

Outras medidas também foram destacadas no referido PDI (UFSCAR, 2004) com o objetivo de impulsionar o estabelecimento de políticas de inclusão, programas ou ações de assistência estudantil e de extensão universitária por parte da UFSCar, o que pode ser percebido em suas Diretrizes Específicas. É o caso de ações como: ampliação e aperfeiçoamento de programas de apoio aos alunos tanto da graduação, quanto da pós-graduação; manutenção da Unidade de Educação Infantil (UAC) da UFSCar e atuação no atendimento da demanda; criação de políticas e atuação na infraestrutura com vistas à permanência de estudantes sem condições financeiras na Universidade; consolidação da política de extensão em vigência com a expansão das atividades extensionistas (UFSCAR, 2004).

Em contrapartida e para consecução desses fins, as Diretrizes Específicas também acenavam aspectos diretamente relacionados ao compromisso da organização e da gestão da Universidade com esse processo, por exemplo: o fornecimento de infraestrutura de equipamentos e pessoal; o acompanhamento, a avaliação e a melhoria do trabalho de suporte às atividades de ensino, de pesquisa e de extensão; e o suporte acadêmico e organizacional para o funcionamento dos cursos noturnos (UFSCAR, 2004).

Frente a tantas metas e, segundo Favato e Ruiz (2018, p. 460), tendo em vista "a precariedade das instituições superiores federais", a proposta do Reuni apareceu para as Universidades como algo atrativo, apesar da clareza de que os investimentos do MEC seriam "atrelados ao cumprimento de metas" e que o atendimento dos planos das Universidades estaria condicionado à própria capacidade orçamentária e operacional do Ministério.

Nesse contexto, a adesão ao Reuni em 2007, pela UFSCar, colocou-se como uma ação de conveniência da gestão da Universidade para recebimento de verbas para consolidação de suas ações, metas e mecanismos de expansão já previstos no seu PDI 2004 (UFSCAR, 2004), ao fornecer parcela importante das verbas necessárias e previstas para esses fins. Até porque, conforme Henriques (2016, p. 48):

Muitas das decisões contidas no PDI da UFSCar estavam em sintonia com as metas e diretrizes pactuadas com o governo através desse Programa, dando assim continuidade na implementação das medidas de aperfeiçoamento de sua estrutura organizacional, conforme traçado em seu plano. Além disso, investimentos de grande porte como os instituídos pelo mesmo, há tempos não vistos, foram facilmente abraçados pela Instituição, tendo em vista os longos períodos de estagnação de seus recursos, déficit de recursos humanos e inércia na expansão de vagas na qual estava inserida. 
Aderir ao Reuni, portanto, além de financeiramente conveniente, tornou-se politicamente importante para UFSCar pela convergência entre seus objetivos de expansão e democratização do ensino e as diretrizes do Programa. Conforme o próprio Relatório de Atividade da UFSCar de 2007 (UFSCAR, 2008, p. 6), o Reuni foi fator fundamental para consolidação da implantação das metas do PDI 2004, tendo em vista que se compatibilizavam, "produzindo como resultado a efetivação de todas as metas do REUNI" e auxiliando a UFSCar, entre outras coisas, a ampliar as vagas e cursos de graduação, pós-graduação e extensão, priorizando os de período noturno.

Para isso, o PDI 2013 (UFSCAR, 2014a), criado posteriormente à adesão da UFSCar ao Programa, vislumbrou novas diretrizes para a Instituição que atuavam no sentido de contribuir com a implementação do Reuni, além de intensificar algumas ações que apareciam nitidamente no PDI 2004 e que já se compatibilizavam com o Reuni, mesmo antes de sua criação.

Entretanto, as dimensões presentes no Reuni - já citadas - e que deveriam ser contempladas nos projetos internos das Universidades que quisessem aderir ao Programa, ganhavam, a partir de então, novas ênfases, tendo, por isso, suas ações intensificadas no PDI 2013 da UFSCar (UFSCAR, 2014a).

Isso indica que, apesar da conveniência financeira da adesão ao Reuni pela referida Universidade, o Programa impactou de forma profunda em seu planejamento estratégico, exigindo atualizações no sentido de identificar avanços e atuar nas dificuldades operacionais enfrentadas pela UFSCar em seu processo de expansão - sobretudo no que diz respeito à insuficiência de sua estrutura física, virtual e humana frente às novas demandas provenientes de uma grande expansão numérica de vagas e matrículas - aliada a um significativo processo de democratização da Universidade - que também passa a ser frequentada, de forma expressiva e inédita, por um novo público estudantil não elitizado e com ingresso proveniente das políticas de ações afirmativas do período. Segundo Henriques (2016, p. 55), com isso:

[...] a UFSCar enfrentaria uma nova realidade. Cursos novos estariam surgindo, sendo que, alguns deles possuíam como característica, uma elevada evasão, além do estímulo ao ingresso de um novo perfil socioeconômico estudantil.

Assim, a partir de 2014, no novo PDI (UFSCAR, 2014a), aprovado já sob a vigência do Reuni - e do Programa da UAB e das políticas de Ações Afirmativas -, a Universidade reafirmou seu compromisso de expansão e seu suporte, definindo uma nova listagem de ações que inter-relacionavam diretamente preocupações referentes aos temas da Ampliação da Oferta de Educação Superior Pública e do Compromisso Social da Instituição, tendo como horizonte a ampliação de acesso e permanência do universitário. Segundo Lourenço (2016), fazia parte do arcabouço de políticas assistenciais da UFSCar voltadas para garantir a formação e permanência dos universitários o oferecimento de diversas bolsas para estudantes de graduação, de pós-graduação e de extensão. No tocante à graduação, por exemplo, foram criadas as chamadas "bolsas assistenciais" (bolsa alimentação, moradia e atividade) e chamadas bolsas específicas (bolsas oferecidas pelo Programa Institucional de Bolsas de Iniciação Científica-PIBIC/ CNPq/UFSCar, bolsa Treinamento, bolsa de Tutoria de Matemática e bolsa de Tutoria de Acolhimento do Programa de Ações Afirmativas) (LOURENÇO, 2016, p. 65). 
Para se entender essa ênfase social adotada no PDI 2013 (UFSCAR, 2014a) pela UFSCar, é importante se considerar que a Taxa de Conclusão da Graduação (TCG) e Alunos Diplomados (DIP) - que, para a referida Universidade, ficou definida como Total de Diplomados e Taxa de Sucesso na Graduação (UFSCAR, 2010) - era um dos indicadores de qualidade definidos pelo MEC no Acordo de Metas no 12 (BRASIL, 2007c) do Reuni. Por isso, como se nota, as ações da Universidade caminhavam no sentido de dar ao novo público ingressante na UFSCar condições materiais para se manter na Instituição e concluir o curso de graduação.

Foi considerado também pelo novo PDI (UFSCAR, 2014a) que, para que ocorresse o maior número possível de ingressos em seus cursos de graduação, a Universidade deveria ter presente em suas Diretrizes Específicas a ideia de revisão dos processos avaliativos para a entrada de estudantes na Universidade "enfrentando dessa forma a evasão e a defasagem educacional, em especial a originada pelas desigualdades sociais” (UFSCAR, 2014a, p.12.).

Nesse sentido, o PDI 2013 (UFSCAR, 2014a) propôs avaliar e aperfeiçoar os processos de seleção de alunos para a graduação, notadamente de estudantes e professores da rede pública de ensino médio, a partir de modalidades diferenciadas de acesso, bem como: aperfeiçoar o vestibular indígena, respeitando suas línguas, culturas e biografias; avaliar, desenvolver e implantar processo de seleção dos cursos de graduação que exigissem prova de conhecimentos específicos. Conforme Lourenço (2016, p. 65), a partir de 2008 também foram realizados processos seletivos diferenciados "para ingresso de refugiados políticos, com a oferta de uma vaga por curso de graduação”, processo seletivo para ingressos indígenas e acordos especiais, como o Programa Estudante Convênio de Graduação (PEC-G), admitindo-se na UFSCar candidatos estrangeiros.

Paralelamente, a Universidade passou ainda a atuar na Renovação Pedagógica da Educação Superior. Nesse caso, é importante se destacar que o Acordo de Adesão ao Reuni (BRASIL, 2007c), assinado entre a UFSCar e o MEC, previa a implantação de 20 novos cursos de graduação e a expansão de 16 já existentes a partir de 2009, trazendo a elevação gradual para $90 \%$ da taxa de conclusão média dos cursos de graduação presenciais. Assim, não é de se estranhar que a questão pedagógica tenha passado a ser focalizada de forma mais intensa pela UFSCar como estratégia para aumento da conclusão de curso pelos estudantes, no sentido da promoção de uma renovação pedagógica.

Por isso, o novo PDI (UFSCAR, 2014a), como indicava o Reuni (BRASIL, 2007b), começou a enfatizar o campo pedagógico como aspecto importante para o aprimoramento da permanência do aluno na Universidade, ao permitir a readequação do curso, considerando as especificidades do novo público atendido. No tocante às suas Diretrizes Específicas, ficou indicada a ideia de se valorizar metodologias de ensino e de processos de ensino e aprendizagem diversificados (como: tradicional e ativo; modalidades presencial e a distância) (UFSCAR, 2014a).

Pode-se notar que tais aspectos já estavam, de algum modo, indicados no PDI 2004 (UFSCAR, 2004), que considerava, todavia, até então, a possibilidade de um novo modelo pedagógico a partir da atuação na formação continuada dos docentes da UFSCar, com vistas a melhorar os "processos de ensinar e aprender" (UFSCar, 2004, p. 13), com base na implantação de uma "política de capacitação contínua didático-pedagógica” dos professores da Universidade, voltadas para o "domínio de novas concepções do processo de ensino e de aprendizagem e de estratégias para o seu desenvolvimento" (UFSCar, 2004, p. 16). Previa-se em paralelo o aprimoramento e a ampliação dos processos de avaliação de desempenho docente 
(UFSCAR, 2004), sinalizando a previsão do aumento de ações de controle sobre o trabalho docente pela Instituição mesmo anteriormente ao Reuni.

O PDI 2004 (UFSCar, 2004) também acenava para o objetivo de fazer uso das tecnologias como aliadas do processo educativo, a fim de contemplar a renovação pedagógica, tal como a reestruturação curricular. A ideia era contribuir e incentivar o uso da metodologia digital na Instituição, bem como, capacitar os estudantes para "uso de tecnologias de informação e comunicação e incentivar a disseminação do conhecimento e uso do software livre nos campi", sobretudo com o aperfeiçoamento dos laboratórios de ensino (UFSCAR, 2004, p. 11-13).

É interessante perceber que, embora o interesse de que o uso das tecnologias nos processos de formação e em todos os aspectos da vida acadêmica já se fizesse presente no PDI 2004 (UFSCAR, 2004), o tema ganhou destaque no PDI 2013 (UFSCAR, 2014a) pelo fato de as Tecnologias da Informação e da Comunicação (TICs) oferecerem as especificidades necessárias para o suposto êxito gerencial e pedagógico nas instituições de ensino, além de desenvolverem uma nova modalidade nas/das relações sociais. Ficou explicitado no PDI 2013 (UFSCAR, 2014a) que a Universidade deveria, entre outras coisas: incentivar tanto o desenvolvimento de novas tecnologias de ensino, como incentivar e fortalecer "a produção e disseminação de conhecimentos em Educação a Distância e tecnologias de informação e comunicação" (UFSCAR, 2014a, p. 19).

Aprofundando-se nas questões de ordem pedagógica, o referido PDI (UFSCAR, 2014a) acenava também para o tema da Reestruturação Acadêmico-Curricular, destacado nas dimensões enfatizadas pelo Reuni (BRASIL, 2007b). De acordo com Carvalho (2014), a flexibilização curricular e a mobilidade estudantil, propostas pelo Reuni, faziam parte das especificidades necessárias para a transformação do ensino superior, propositadas pelo Governo Federal; assim, as IFES deveriam aderir aos bacharelados interdisciplinares ou criarem propostas de mobilidades, flexibilizações e inovações curriculares próprias para atender o novo perfil de estudante que chegaria às IFES. Nesse caso, a meta na UFSCar foi o oferecimento de cursos de graduação com propostas pedagógicas flexíveis, apresentando nuanças de reestruturação curricular, porém, com ênfase na flexibilidade e no enlace entre o ensino, a pesquisa e a extensão, junto ao uso das tecnologias (UFSCAR, 2004).

Portanto, o que se observa é que, no PDI 2013 (USFCAR, 2014a), a reestruturação curricular buscou a qualidade por meio da implementação de regimes curriculares e sistemas de títulos que possibilitassem a construção de itinerários formativos, como demandado pelo Reuni (BRASIL, 2007b, p. 11), sobretudo em sua dimensão número 2 (Reestruturação Acadêmico-Curricular) e no que diz respeito ao tema da Reestruturação Acadêmico-Curricular e da Renovação Pedagógica da Educação Superior.

Ainda que a questão da interdisciplinaridade fosse prevista pelo PDI 2004 (UFSCAR, 2004), a questão mais específica da Mobilidade Intra e Interinstitucional - que favoreceria a mobilidade do estudante frente ao aproveitamento de créditos, bem como, de sua circulação entre cursos, programas e instituições de educação superior --, não foi abordada diretamente por ele. O documento limitou-se a acenar que caberia à Instituição "promover condições para o trabalho interdisciplinar em ensino, pesquisa e extensão na UFSCar, intra e intercursos, grupos, redes e projetos", bem como criar oportunidades para que as atividades acadêmicas desenvolvidas pelo estudante fossem incorporadas como atividades curriculares (UFSCAR, 2004, p. 26). 
Os aspectos referentes à Mobilidade Intra e Interinstitucional só foram efetivamente enfatizados no PDI 2013, considerando as orientações do Reuni nesse sentido - "Promoção da ampla mobilidade estudantil mediante o aproveitamento de créditos e a circulação de estudantes entre cursos e programas, e entre instituições de educação superior" (UFSCAR, 2014a, p. 11) -, de modo que caberia à instituição atuar com vistas a: expandir, diversificar, consolidar e valorizar o trabalho interdisciplinar em ensino, pesquisa e extensão na UFSCar e com outras instituições de ensino e pesquisa (UFSCAR, 2014a).

Com base nessas alterações de ordem curricular, didática e pedagógica dos cursos, bem como, do realce para seu caráter intra e interinstitucional, a ideia do novo PDI (UFSCAR, 2014a) passou ainda para a focalização dos resultados dessas alterações, pela consideração do próprio rendimento do aluno, interpretado como elemento fundamental para se obter sucesso na manutenção e permanência estudantil na UFSCar. Destarte, outras ações de Compromisso Social da Instituição foram colocadas para si pela própria Universidade, que deveria aprimorar seus mecanismos para acompanhamento de seus egressos (UFSCAR, 2014a), bem como, realizar procedimentos de "diagnóstico e indicadores para acompanhamento de disciplinas com altos índices de reprovação, visando a identificação de possíveis causas e sua solução" (UFSCAR, 2014a, p. 8), aspectos até então desconsiderados no PDI anterior (UFSCAR, 2004), e que acabaram postos e enfatizados nessa fase, impulsionando a construção de novas ferramentas avaliativas e reguladoras por parte da Instituição. Nesse caso, destaca-se também a movimentação da Universidade no sentido do atendimento do indicador de qualidade relacionado à quantidade de alunos diplomados produzidos anualmente pela UFSCar, presente tanto no documento do MEC (BRASIL, 2008), quanto da UFSCar (UFSCAR, 2010), e a taxa de sucesso na graduação, criado pela UFSCar (UFSCAR, 2010).

O Suporte da Pós-Graduação ao Desenvolvimento e Aperfeiçoamento Qualitativo dos Cursos de Graduação também já era considerado como fator primordial desse processo desde o PDI 2004. O referido PDI enfatizava em suas Diretrizes Específicas a necessidade de se "estabelecer e implementar uma política de avaliação permanente da formação propiciada pelos cursos de graduação", resultando em possíveis reformulações de seus projetos pedagógicos; tal como "implantar um processo institucional de avaliação da pós-graduação da UFSCar" (UFSCAR, 2004, p. 26-7). Tais aspectos sinalizavam a tendência reguladora da Instituição já presente na Universidade anteriormente ao Reuni, com a indicação de seu interesse de atuação a partir de mecanismos de avaliação de seus cursos de graduação e pós-graduação e que, posteriormente ao Reuni, por iniciativa da própria Universidade, passaram a contar com indicadores resgatados de documentos do MEC de 2002 (BRASIL. TCU, 2004), para regulação da Instituição, como: Conceito CAPES para Pós-Graduação, Índice de Qualificação do Docente, Taxa de Sucesso na Graduação.

Apesar dessas observações, o que se constata é que, após o Reuni, no PDI 2013 (UFSCAR, 2014a), a questão da pós-graduação ganhou nova ênfase como ferramenta para o aprimoramento da graduação, ao ser colocada como diretriz do Programa a ideia de "Suporte da pós graduação" para desenvolvimento e aperfeiçoamento qualitativo dos cursos da graduação (BRASIL, 2007b, p. 11). Segundo o PDI 2013 (UFSCAR, 2014a), caberia à Instituição definir e implementar uma política institucional voltada para a formação na pós-graduação, que considerasse sua integração com os cursos de graduação; bem como fomentar e implementar 
discussão na comunidade, com vistas à integração da pós-graduação e graduação; assim como, avaliar o impacto das atividades da pós-graduação na graduação.

Dessa maneira, o que se percebe pela análise dos Planos da UFSCar é que a expansão da Universidade, planejada e programada em seu PDI 2004 (UFSCAR, 2004), foi potencializada em seu PDI 2013 (UFSCAR, 2014a) por meio de suas 39 Diretrizes Gerais e em suas Diretrizes Específicas, que reforçaram alguns aspectos de seu PDI anterior e destacaram novos elementos provenientes do Reuni para operacionalização da expansão física e humana, bem como da democratização da Universidade. Tais informações ficam evidentes nos Relatórios Anuais de Atividades (UFSCAR, 2008; 2010; 2011; 2013; 2014b; 2016) produzidos pela UFSCar sobre a vigência do Reuni, que revelam que, apesar das conquistas atribuídas pela Universidade ao Programa, elas não foram suficientemente respaldadas em termos financeiros pelo Reuni frente à expansão e democratização materializada. Como resume Fonseca (2016, p. 99):

Para a UFSCar, a expansão com o Programa Reuni em 2007 foi uma oportunidade para o seu desenvolvimento, conforme o planejado no seu PDI 2004, permitindo um aumento de vagas em curto espaço de tempo, porém com limitações, e se não foi o ideal, foi o crescimento possível.

Assim, conforme o Relatório de 2009 (UFSCAR, 2010), não obstante o projeto Reuni na UFSCar ser de grande importância para a ampliação da graduação e da pós-graduação:

[...] os recursos pactuados mostraram-se insuficientes para a execução em todo o horizonte previsto para o projeto. Neste sentido, a UFSCar solicitou aportes adicionais à $\mathrm{SESu} / \mathrm{MEC}$, tendo sido atendida, porém em um montante insuficiente (UFSCAR, 2018, p. 37).

O Relatório 2009 (UFSCAR, 2010), por sua vez, também explicitou que, a despeito da contratação de novos servidores, entre os anos de 2006 e 2009, a Pró-Reitoria de Graduação da Universidade (ProGrad) não tinha capacidade de atender o:

[...] imenso conjunto de necessidades e tarefas geradas pela expansão da UFSCar, em atendimento às demandas do REUNI" ("realização de eventos como Processos Seletivos, Matrícula, Seminário de Inovações Pedagógicas, Calourada, Universidade Aberta, Feira de Oportunidades, Cerimônias de Colação de Grau, Gestão de Bolsas, Registro Acadêmico, Revalidação de Diplomas, Gestão dos Estágios e de outras (UFSCAR, 2010, p. 61).

Até mesmo o Departamento de Atenção à Saúde (DeAS) da UFSCar, segundo o Relatório 2016 (UFSCAR, 2017), estava enfrentando dificuldades, tendo em vista a ampla lista de espera para atendimento psicológico, por conta da ampliação do número de alunos da Universidade desde o Reuni, considerando que o número dos profissionais continuou o mesmo.

Ainda, de acordo com o Relatório 2010 (UFSCAR, 2011), a implantação dos novos cursos criados dentro do programa Reuni, em 2009, geraram muito trabalho para as instâncias internas da UFSCar (como a Coordenadoria de Desenvolvimento Pedagógico/CDP e a Divisão de Controle Acadêmico/DiCA), no processo de análise, aprovação das disciplinas novas e alteração das existentes, bem como para a inserção de dados em seus sistemas virtuais - como 
o ProGradWeb (Sistema Virtual da Pró-Reitora de Graduação) e o Sistema de Desenvolvimento do Processo de Ensino e Aprendizagem da UFSCar (Nexos) -, que passaram a demandar progressivamente mais intervenções de manutenção e aperfeiçoamento na tentativa de adequá-los às demandas. Isso porque, segundo Carvalho (2016, p. 99), a ampliação das unidades administrativas elevou o volume de trabalho, dando margem para "procedimentos ainda não formalizados, à falta de clareza nos processos decisórios administrativos e uma infraestrutura precarizada pela falta de espaços físicos adequados, de mobiliários e de equipamentos".

Em relação à contratação de servidores, de acordo com Blanco (2014), após a adesão do Reuni, as IFES precisaram contratar novos servidores públicos que passaram a receber formação continuada para conseguirem acompanhar as transformações na cultura institucional provenientes desse processo.

Tudo isso, conforme o Relatório 2012 (UFSCAR, 2013, p. 130), ocasionou um aumento de atividades financiadas com verbas da própria Instituição, implicando o desafio de se encontrar "novas fontes de recursos próprios e/ou revisar os existentes, sempre de forma aceitável e adequada"; e um novo perfil de demandas às áreas acadêmicas e administrativas, exigindo a revisão do modelo usado na distribuição interna de recursos.

\section{CONSIDERAÇões FINAIS}

Conforme se nota pelo estudo exposto, o Reuni apresentou-se às Universidades como:

[...] um 'convite' à reestruturação e expansão, com um apelo sedutor, sintetizado no Artigo $6^{\circ}$. que determina: "A proposta, se aprovada pelo Ministério da Educação, dará origem a instrumentos próprios, que fixarão os recursos financeiros adicionais destinados à universidade, vinculando os repasses ao cumprimento das etapas" (LÉDA; MANCEBO, 2009, p. 54).

Para a UFSCar, em especial, ele se mostrou como fator fundamental para a consolidação e implantação das metas de seu PDI 2004 (UFSCAR, 2004), na medida em que os mecanismos de expansão e democratização da UFSCar - definidos em metas - já estavam presentes nele, indo ao encontro do previsto no Reuni, que estabelecia como suas “dimensões" (BRASIL, 2007b, p. 11) de atuação, aspectos já considerados pela UFSCar anteriormente à sua implementação.

Nesse sentido, a adesão da UFSCar ao Reuni, em 2007, pode ser entendida como uma ação de conveniência financeira assumida pela gestão da Universidade para recebimento de verbas para consolidação de suas ações, metas e mecanismos de regulação já previstos no seu primeiro PDI 2004 (UFSCAR, 2004). Por essa razão, o PDI 2013 (UFSCAR, 2014a), que foi elaborado após a adesão da UFSCar ao Programa, trouxe outras diretrizes para a Instituição no sentido de operar a implantação do Reuni, intensificando, por sua vez, ações presentes desde o PDI 2004 e que já eram coerentes com o Reuni, mesmo antes de sua formulação.

Carvalho (2011) explica que as IFES que não realizaram estudos exploratórios, nem elaboraram PDI, anteriormente ao Reuni, não conseguiram implementar, nem consolidar as propostas do Programa. Já as IFES que se prepararam para os processos de expansões, iniciados em 2003, conseguiram atingir parcial ou totalmente as metas Reuni, inclusive porque passaram 
a desenvolver ações sociais para oferecer aos estudantes condições de permanência nas IFES, como programas de assistências estudantis, monitorias acadêmicas, com vistas a atuar na consolidação da meta de reduzir o número de evasões nos cursos de graduação presenciais. Tal explicação certamente ajuda na compreensão do processo de implantação do Reuni na UFSCar apresentado neste estudo.

Todavia, a nova ênfase trazida pelo referido Programa no PDI 2013 da UFSCar (UFSCAR, 2014a) se deu sobretudo em aspectos referentes às ações sociais, pedagógicas e curriculares da Universidade como estratégias para a redução das taxas de evasão, tendo em vista o novo público ingressante na Instituição - via Reuni e Políticas de Ações Afirmativas - e girando em torno: de políticas de inclusão e programas de assistência estudantil, com destaque para a extensão universitária; da articulação da graduação com a pós-graduação como ferramenta de suporte à primeira; da reorganização dos cursos de graduação, com diversificação em suas modalidades, assim como com a implantação de regimes curriculares e sistemas de títulos pensados para a construção de itinerários formativos e para a circulação de estudantes entre cursos, programas e instituições de educação superior; da atualização de metodologias, com ênfase no uso de tecnologias para os processos de ensino-aprendizagem; da criação de mais ferramentas avaliativas seja de cursos, processos ou docentes.

Como se nota, apesar da conveniência financeira da adesão ao Reuni pela UFSCar, pode-se concluir que o referido Programa acabou atuando de forma significativa no planejamento estratégico da Instituição ao exercer forte impacto em seu PDI 2013 (UFSCar, 2014a), gerando novas demandas e ênfases, bem como o aprofundamento de algumas delas, agindo no sentido de intensificar ações e políticas reguladoras da UFSCar com vistas ao cumprimento do Contrato de Adesão (BRASIL, 2007c) firmado com o MEC em um contexto de precariedade orçamentária.

\section{REFERÊNCIAS}

BLANCO, Solange Machado. Gestão universitária discursiva: ressignificando a competência comunicativa com a educação a distância, 2014, 186s. Dissertação (Mestrado em Sociologia e Direito). Universidade Federal Fluminense, Niterói, 2014.

BRASIL. TCU. Orientações para o cálculo dos indicadores de gestão - Decisão TCU n ${ }^{\circ}$. 408/2002 - Plenário. Brasília, março de 2004. Disponível em: http:/ / portal.mec.gov.br/sesu/ arquivos/pdf/indicadores.pdf . Acesso em: 22 nov. 2019.

BRASIL. Decreto n. 5.800, de 8 de junho de 2006a. Dispõe sobre o Sistema Universidade Aberta do Brasil - UAB. Diário Oficial da União [da] República Federativa do Brasil, Brasília, DF, 9 jun. 2006a. Disponível em: http://www.planalto.gov.br/ccivil_03/_Ato20042006/2006/Decreto/D5800.htm Acesso em: 21 nov. 2019.

BRASIL. Ministério da Educação. Expansão das universidades federais: o sonho se torna realidade! Período de 2003 a 2006. Brasilia: SESu, 2006b. Disponível em: http://portal.mec. gov.br/sesu/arquivos/pdf/relatorioexecutivo.pdf. Acesso em: 12 fev. 2020. 
BRASIL. Decreto nº 6.096, de 24 de abril de 2007a. Institui o Programa de Apoio a Planos de Reestruturação e Expansão das Universidades Federais - Reuni. Diário Oficial da União [da] República Federativa do Brasil, Brasília, DF, 25 abr. 2007a.

BRASIL. REUNI - Reestruturação e expansão das universidades federais: diretrizes gerais. Brasília, DF, ago. 2007b, mimeo. Disponível em: http:/ / portal.mec.gov.br/sesu/arquivos/pdf/diretrizesreuni.pdf. Acesso em: 2 nov. 2019.

BRASIL. Acordo de Metas n. 12, de março de 2008, que entre si celebram a União representadas pelo Ministério da Educação por intermédio da Secretaria de Educação Superior e a Universidade Federal de São Carlos para os fins que especifica o Decreto n. 6.096 de 27 de abril 2007c. Disponível em: http://www.reuni.ufscar.br/documentos. Acesso em: 22 nov. 2019.

BRASIL. Lei $\mathbf{n}^{\mathbf{0}}$. 12.711, de 29 de agosto de 2012. Dispõe sobre o ingresso nas universidades federais e nas instituições federais de ensino técnico de nível médio e dá outras providências. Diário Oficial da União [da] República Federativa do Brasil, Brasília, DF, 30 ago. 2012. Disponível em: http://www.planalto.gov.br/ccivil_03/_ato2011-2014/2012/lei/112711.htm. Acesso em: 21 nov. 2019.

CARVALHO, Maria de Lourdes de. A influência das dimensões do protocolo $5 \mathrm{c}$ na implementação da política pública de ampliação do acesso ao ensino superior, 2011, $97 \mathrm{f}$. Dissertação (Mestrado em Administração). Universidade Federal de Viçosa, Viçosa, 2011.

FAVATO, Maria Nilse Favato; RUIZ, Maria José Ferreira. REUNI: política para a democratização da educação superior? Revista Eletrônica de Educação, v. 12, n. 2, p. 448-463, mai./ago. 2018. Disponível em: http://www.reveduc.ufscar.br/index.php/reveduc/article/ view/2365/710. Acesso em: 13 fev. 2020.

HENRIQUES, Franciele Lagni. Políticas Públicas de expansão universitária: uma análise do Programa Reuni na UFSCar no período de 2007 a 2014, 2016, 103s. Dissertação (Mestrado em Gestão de Organizações e Sistemas Públicos). Universidade Federal de São Carlos, São Carlos, 2016.

KUENZER, Acácia Zeneida (1998). Desafios teórico-metodológicos da relação trabalho-educação e o papel social da escola. In: FRIGOTTO, G. (Org.). Educação e crise do trabalho: perspectivas de final de século. Petrópolis, RJ: Vozes, 1998, p. 55-75.

LÉDA, Denise Bessa; MANCEBO, Deise. REUNI: heteronomia e precarização da universidade e do trabalho docente. Revista Educação \& Realidade, v. 34, n. 1, p. 49-64, jan./abr. 2009. Disponível em: https://seer.ufrgs.br/educacaoerealidade/article/view/8457. Acesso em: 13 fev. 2020.

LOURENÇO, Patrícia do Espírito Santo Fonseca. O impacto da expansão provocada pelo Programa Reuni na estrutura organizacional da Universidade Federal de São Carlos. 
Programa de Pós-Graduação em Processos de Ensino, Gestão e Inovação - Universidade de Araraquara (UNIARA), 2016, 126s. Dissertação (Mestrado em Processos de Ensino, Gestão e Inovação). Centro Universitário de Araraquara, Araraquara, 2016.

OTRANTO, Célia Regina. A reforma da educação superior do governo Lula da Silva: da inspiração à implantação. REUNIÃO ANUAL DA ANPED, 29, 2006, Caxambu, Anais... Caxambu, 2006, p. 1-19. Disponível em: http://www.anped.org.br/biblioteca/item/reforma-da-educacao-superior-do-governo-lula-da-inspiracao-implantacao. Acesso em: 14 fev. 2020.

UFSCAR. PDI 2013. Histórico. São Carlos: UFSCar, online. Disponível em: http:/ /www.pdi. ufscar.br/. Acesso em: 20 nov. 2019.

UFSCAR. Plano de Desenvolvimento Institucional. São Carlos: UFSCar, 2004. Disponível em: http://www.pdi.ufscar.br/documentos/plano-de-desenvolvimento-institucional-da-ufscar-.pdf . Acesso em: 20 nov. 2019.

UFSCAR. Plano de Desenvolvimento Institucional. São Carlos: UFSCar, 2014a. Disponível em: http://www.pdi.ufscar.br/diretrizes-gerais-especificas-e-para-gestao-do-espaco-fisico. Acesso em: 20 nov. 2019.

UFSCAR. Relatório anual de atividades 2007. São Carlos, 2008, 162p. Disponível em: http://www.spdi.ufscar.br/documentos/Anos-anteriores/relatorio-de-atividades. Acesso em: 22 nov. 2019.

UFSCAR. SPDI. Relatório anual de atividades 2009. São Carlos, 2010, 164p. Disponível em: http://www.spdi.ufscar.br/documentos/Anos-anteriores/relatorio-de-atividades. Acesso em: 22 nov. 2019.

UFSCAR. Relatório anual de atividades 2010. São Carlos, 2011, 222p. Disponível em: http://www.spdi.ufscar.br/documentos/Anos-anteriores/relatorio-de-atividades . Acesso em: 22 out. 2018.

UFSCAR. Relatório anual de atividades 2012. São Carlos, 2013, 269p. Disponível em: http://www.spdi.ufscar.br/documentos/Anos-anteriores/relatorio-de-atividades . Acesso em: 22 out. 2018.

UFSCAR. Relatório anual de atividades 2013. São Carlos, 2014b, 432p. Disponível em: http://www.spdi.ufscar.br/documentos/Anos-anteriores/relatorio-de-atividades . Acesso em: 22 nov. 2019.

UFSCAR. Relatório anual de atividades 2015. São Carlos, 2016, 365p. Disponível em: http://www.spdi.ufscar.br/documentos/Anos-anteriores/relatorio-de-atividades . Acesso em: 22 nov. 2019. 
UFSCAR. Relatório anual de atividades 2016. São Carlos, 2017, 365p. Disponível em: http://www.spdi.ufscar.br/documentos/Anos-anteriores/relatorio-de-atividades. Acesso em: 22 out. 2018.

UFSCAR. Relatório anual de atividades 2017. São Carlos, 2018, 407p. Disponível em: http://www.spdi.ufscar.br/documentos/Anos-anteriores/relatorio-de-atividades . Acesso em: 22 out. 2018.

\section{Dados das autoras:}

\section{Géssica Priscila Ramos}

Doutorado em Educação pela Universidade Federal de São Carlos. São Carlos/SP-Brasil. Professora do Programa de Pós-Graduação em Educação da Universidade Federal de São Carlos. São Carlos/SP-Brasil.gessicaramos@yahoo.com.br

\section{Ana Paula Silveira}

Doutoranda no Programa de Pós - Graduação em Educação pela Universidade Federal de São Carlos. São Carlos/SP-Brasil. Professora Licenciada do Município de Pitangueiras/SP-Brasil. a_silveirapaula@yahoo.com.br

\section{Priscila de Paulo Uliam Martins}

Mestre em Educação pela Universidade Federal de São Carlos. São Carlos/SP-Brasil. Professora de Ciências na Växjö International Elementary School em Växjo-Suécia. priscilauliam@gmail. com

Submetido em: 19-2-2020

Aceito em: 17-11-2020 